\title{
Combination of Rimonabant and Donepezil Prolongs Spatial Memory Duration
}

\author{
Laura E Wise', Philip A Iredale ${ }^{2}$, Rene J Stokes' and Aron H Lichtman*,' \\ 'Department of Pharmacology and Toxicology, Virginia Commonwealth University, Richmond, VA, USA; ${ }^{2}$ Central Research Division, Pfizer, Inc., \\ Groton, CT, USA
}

\begin{abstract}
The observations that the cannabinoid ${ }_{1}\left(\mathrm{CB}_{\mathrm{I}}\right)$ receptor antagonist/inverse agonist, rimonabant, and the selective noncompetitive inhibitor of acetylcholinesterase (AChE), donepezil, improve performance in a variety of animal memory models, suggest that these neurochemical systems play integral roles in cognition. The present study tested whether each of these agents administered alone or in combination will prolong the duration of spatial memory. Rats were trained in a two-phase radial-arm maze procedure, consisting of acquisition and retrieval tests, which were separated by an $18 \mathrm{~h}$ delay. Each drug was administered $30 \mathrm{~min}$ before the acquisition phase, immediately after the acquisition phase, or 30 min before the retrieval test to assess acquisition/consolidation, consolidation, and retrieval mnemonic processes, respectively. Rimonabant or donepezil administered before the acquisition phase, but not immediately after acquisition or before retrieval, led to a significant decrease in the number of errors committed during the retrieval test. Combined administration of subthreshold doses of rimonabant and donepezil that had no discernable effects on performance when given alone, enhanced memory. These results taken together demonstrate that the delay radial-arm maze task is sufficiently sensitive to detect memory enhancing effects of these drugs. Moreover, these findings suggest that combined administration of subthreshold doses of rimonabant and donepezil can improve memory and may represent a novel approach to treat cognitive deficits associated with neurodegenerative disorders. Neuropsychopharmacology (2007) 32, I805- I8I2; doi:I0.1038/sj.npp. I30 I297; published online I0 January 2007
\end{abstract}

Keywords: radial-arm maze; SRI4I7I6 (Rimonabant); donepezil (Aricept); endogenous cannabinoid; acetylcholinesterase inhibitor; spatial memory

\section{INTRODUCTION}

The centrally occurring endocannabinoid system consists of the G-protein coupled receptor cannabinoid ${ }_{1}\left(\mathrm{CB}_{1}\right)$ (Matsuda et al, 1990) and endogenous ligands, anandamide (Devane et al, 1992) and 2-arachidonyl glycerol (2-AG) (Mechoulam et al, 1995; Sugiura et al, 1995), that bind to and activate these receptors. The high concentration of $\mathrm{CB}_{1}$ receptors (Herkenham et al, 1991) and the presence of anandamide and 2-AG in the hippocampus and other forebrain regions associated with memory function (Felder et al, 1996; Di Marzo et al, 2000) are consistent with the notion that the endocannabinoid system modulates cognitive processes. Administration of the $\mathrm{CB}_{1}$ receptor antagonist rimonabant (SR 141716) (Rinaldi-Carmona et al, 1995) has been reported to enhance memory in delayed radialarm maze tasks (Lichtman, 2000; Wolff and Leander, 2003), a social recognition memory paradigm (Terranova et al,

\footnotetext{
*Correspondence: Dr AH Lichtman, Department of Pharmacology and Toxicology, Virginia Commonwealth University, Medical College of Virginia Campus, PO Box 980613, Richmond, VA 23298-0613, USA, Tel: + | 804828 8480, Fax: + | 8048282117 ,

E-mail: alichtma@vcu.edu

Received 31 July 2006; revised 20 September 2006; accepted 3 November 2006
}

1996), and an elevated T-maze task (Takahata et al, 2005). Interestingly, intrahippocampal administration of rimonabant in food-storing birds enhanced memory for the location of a hidden food reward (Shiflett et al, 2004). Additionally, $\mathrm{CB}_{1}$ receptor knockout mice performed better than wild-type control mice in a two-trial object recognition task (Reibaud et al, 1999). These findings taken together suggest that the $\mathrm{CB}_{1}$ receptor antagonist rimonabant may enhance mnemonic processes.

The central cholinergic system has long been known to play a key role in learning and memory. Cholinergic neurons degenerate in patients with Alzheimer's disease as well as senile dementia, and, importantly, the degree of degeneration highly correlates with functional loss in these disorders (Davies and Maloney, 1976; Perry et al, 1978a, b). Clinical trials revealed that donepezil (Aricept, previously E2020, Pfizer), a selective noncompetitive inhibitor of acetylcholinesterase (AChE; see Sugimoto et al (2002) for a review), had cognitive benefits in Alzheimer's disease patients afflicted with mild to moderate degrees of dementia (Mintzer and Kershaw, 2003). Presently donepezil is used to treat cognitive deficits associated with Alzheimer's disease (Rogers and Friedhoff, 1998; Doody, 1999; Grutzendler and Morris, 2001). Additionally, this drug has been found to reverse memory deficits in variety of rodent models of 
learning and memory. Donepezil reversed scopolamineinduced impairments in spontaneous alternation in the Tmaze in young and aged mice as well as in a delayed nonmatch to place task in the radial-arm maze (Bontempi et al, 2003). Repeated administration of donepezil improved the memory performance of aged rats in the Morris water maze (Hernandez et al, 2006) and reversed amyloid $\beta$-induced memory impairments in a delayed matching to position paradigm (Yamada et al, 2005). Additionally, this agent reversed learning impairments in the passive avoidance task induced by lesions in the nucleus basalis magnocellularis and scopolamine (Cheng et al, 1996; Ogura et al, 2000), and ethylcholine mustard aziridinium ion (AF64A) (Cheng and Tang, 1998) induced impairments in eight-arm radial maze tasks (Braida et al, 1996).

Although there is evidence demonstrating that rimonabant or donepezil enhances performance in rodent models of learning and memory and that the cannabinoid and cholinergic receptor systems have important roles in learning and memory, no study has examined whether coadministration of these drugs would further enhance memory. Therefore, the main goal of the present study was to determine whether concomitant administration of inactive doses of rimonabant and donepezil would enhance memory as assessed in a rat radial-arm maze delay paradigm. The task employed a two-phase procedure, acquisition, and test phases, which were separated by an $18 \mathrm{~h}$ delay in order to increase the task difficulty. The doseresponse relationship of each drug administered $30 \mathrm{~min}$ before the acquisition phase was evaluated. In addition, each drug was given immediately after the acquisition phase or $30 \mathrm{~min}$ before retrieval testing to infer whether these compounds influenced consolidation and retrieval processes, respectively. Finally, inactive doses of these drugs were given in combination to determine whether they would enhance memory performance.

\section{MATERIALS AND METHODS}

\section{Subjects}

The subjects consisted of two groups of Sprague-Dawley (Harlan, IN) male rats that were between 3 and 11 months of age. The animals were individually housed in a temperature-controlled $\left(20-22^{\circ} \mathrm{C}\right)$ environment, with a $12 \mathrm{~h}$ light/dark cycle. Subjects were placed on a foodrestricted diet in order to maintain a weight between 280 and $320 \mathrm{~g}$, approximately $85 \%$ of their free-feeding weight. Each rat was given between 12 and $16 \mathrm{~g}$ of food rations/day, and water was available ad libitum at all times except during the training and test sessions. All experiments were approved by the Institutional Animal Care and Use Committee of Virginia Commonwealth University.

\section{Drugs}

Rimonabant (National Institute on Drug Abuse, Rockville, MD) and donepezil (gift from Pfizer, Inc., Groton, CT) were dissolved in a 1:1 mixture of absolute ethanol and alkamuls620 (Rhone-Poulenc, Princeton, NJ), and diluted with saline in a final ratio of 1:1:18 (ethanol/alkamuls/saline). All injections were given through the i.p. route of administration in a volume of $1 \mathrm{ml} / \mathrm{kg}$.

\section{Apparatus and Training}

The initial radial-arm maze training procedures were identical to that previously described (Lichtman and Martin, 1996; Lichtman, 2000). Each of the eight arms was baited with a $45 \mathrm{mg}$ rodent formula, dustless precision pellets (Bioserve, Frenchtown, NJ) placed $5 \mathrm{~cm}$ from the end. After a subject visited each arm and obtained all the food pellets, with one or no re-entries into a previously visited arm in three consecutive sessions, it was trained in a repeated acquisition version of the task that incorporated acquisition and retrieval test phases. During the acquisition phase, one of the arms was randomly selected and a Plexiglas barricade blocked its entryway. Each of the remaining seven arms was baited with a food pellet before the subject's placement in the maze. After the subject entered the seven available arms and consumed all the food pellets, it was removed from the maze and returned to its home cage. While undergoing training, the subject returned to the maze for the test phase $10 \mathrm{~min}$ after the acquisition phase. During the test phase, all eight arms were available; however, only the previously blocked arm was baited with a food pellet. The number of entries and the duration of time required for each subject to enter the seven available arms and consume the food pellet(s) were recorded for each phase. Subjects qualified for drug testing once they committed one or no errors in both the acquisition and test phases on three consecutive sessions. Subjects were given a maximum of two tests/week.

An initial experiment evaluated the relationship between the duration of the delay and performance during the retrieval test. Subjects were given repeated acquisition training and given delays of various durations (ie $10 \mathrm{~min}, 1$, 2,6 , or $18 \mathrm{~h}$ ) before the retrieval test. Based on the results of this initial study, all subsequent experiments imposed an $18 \mathrm{~h}$ delay between the two phases in order to optimize the likelihood of detecting a drug-induced enhancement in performance.

In Experiment 2, we evaluated the effects of rimonabant $(0.3,1$, and $3 \mathrm{mg} / \mathrm{kg})$ and donepezil $(0.1,0.3$, and $1 \mathrm{mg} / \mathrm{kg})$ given $20 \mathrm{~min}$ before the acquisition phase on performance. The dose range selected for each drug was based on previous studies (Cheng et al, 1996; Lichtman and Martin, 1996; Cheng and Tang, 1998; Lichtman, 2000; Ogura et al, 2000; Tokita et al, 2002; Bontempi et al, 2003; Wolff and Leander, 2003) that demonstrated performance-enhancing effects in memory tests.

In the third experiment, we assessed the effects of rimonabant $(1 \mathrm{mg} / \mathrm{kg})$ or donepezil $(0.3 \mathrm{mg} / \mathrm{kg})$ given either immediately after acquisition or $30 \mathrm{~min}$ before the retrieval test. These respective doses were selected based on the observation of each significantly enhanced performance in the second experiment.

In the final experiment, a combination of subthreshold doses of rimonabant $(0.3 \mathrm{mg} / \mathrm{kg})$ and donepezil $(0.1 \mathrm{mg} / \mathrm{kg})$ were given $20 \mathrm{~min}$ before the acquisition phase. When combination doses were tested, donepezil or vehicle was administered approximately 2 min before either rimonabant 
or vehicle. The treatments in each experiment were counterbalanced to control for any order effects.

\section{Statistical Analysis}

An observer scored the number of correct responses and errors (ie entries into unbaited arms) committed by each rat and the amount of time taken to obtain all the available food pellets for each phase. The dependent measures of interest were the number of errors committed and the time required for each rat to complete each phase of the task. Withinsubject analysis of variances (ANOVAs) were used to analyze each dependent measure. Dunnett's post hoc test was used in each of the dose-response studies to analyze differences between vehicle and each dose of drug. The Tukey-Kramer post hoc test was used to analyze differences in the drug interaction experiment. Differences were considered significant at the $p<0.05$ level.

\section{RESULTS}

\section{The Effects of Varying Delays on Test Phase Performance}

As shown in Figure 1, increasing the delay duration between the two phases led to a significant decrease in choice accuracy during the retrieval test, $\mathrm{F}(4,68)=17.4, p<0.01$. The subjects committed significantly more errors following delays of 2,6 , and $18 \mathrm{~h}$ than the number of errors made following the $10 \mathrm{~min}$ delay $(p<0.01)$. Performance was virtually perfect during the acquisition phase, as subjects rarely made any errors and therefore is not shown here or in subsequent experiments. The rate of arm entry was approximately $10 \mathrm{~s} / \mathrm{arm}$ and was unaffected by increasing delays, $\mathrm{F}(4,68)=1.0, p>0.05$ (data not shown). Based on these results, an $18 \mathrm{~h}$ delay was selected for subsequent studies to ensure that the task was sufficiently difficult to observe drug-induced improvements in the retrieval test phase.

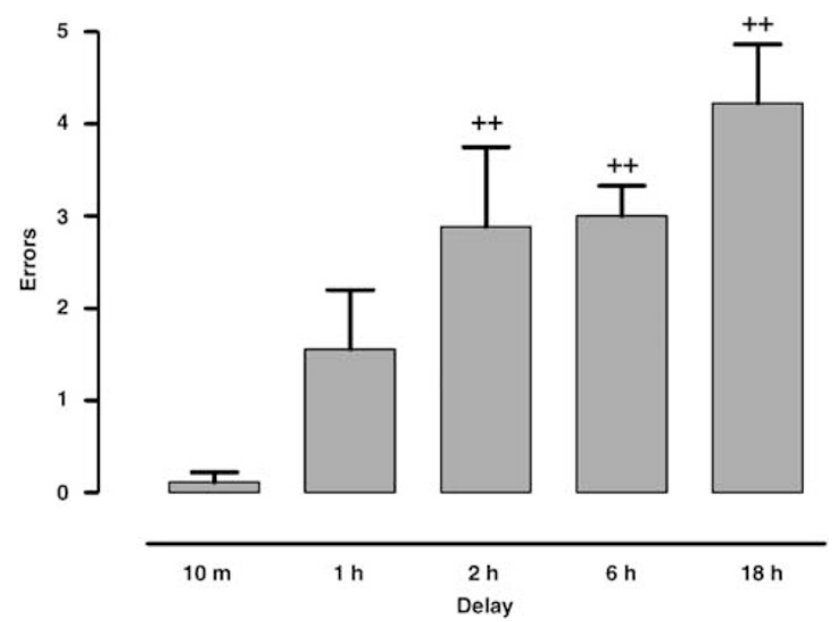

Figure I Increasing delay duration leads to an increase in the number of errors committed in the test phase. ${ }^{++} p<0.0$ I (Dunnett's post hoc test) for each delay condition vs the 10 min delay. Results are shown as mean $\pm S E ; n=18$ rats/group

\section{Rimonabant or Donepezil Enhances Memory}

We have previously found that a single dose of rimonabant $(3 \mathrm{mg} / \mathrm{kg})$ enhanced performance in the radial-arm maze delay paradigm when given before acquisition, but not when administered immediately after acquisition or before retrieval (Lichtman, 2000). However, in an adapted version of this task, Wolff and Leander (2003) found that rimonabant given immediately after acquisition enhanced performance during the retrieval test. Therefore, in these series of experiments we sought to investigate further the efficacy of rimonabant in this task given before acquisition, immediately after acquisition, or before retrieval testing, as well as to establish its dose-response relationship. Additionally, we evaluated donepezil in a similar series of experiments. Rimonabant (Figure 2a; $\mathrm{F}(3,24)=4.3, p<0.05$ ) or donepezil (Figure $2 \mathrm{~b} ; \mathrm{F}(3,30)=5.4, p<0.01$ ) given before the acquisition session led to significant dose-related reductions in the number of errors committed during the retrieval test. The $1.0 \mathrm{mg} / \mathrm{kg} \quad(p<0.01)$ and $3.0 \mathrm{mg} / \mathrm{kg}$ $(p<0.01)$ doses of rimonabant, and the $0.3 \mathrm{mg} / \mathrm{kg}$ $(p<0.01)$ and $1.0 \mathrm{mg} / \mathrm{kg}(p<0.01)$ doses of donepezil, reduced the number of errors compared to their respective vehicle treatments.
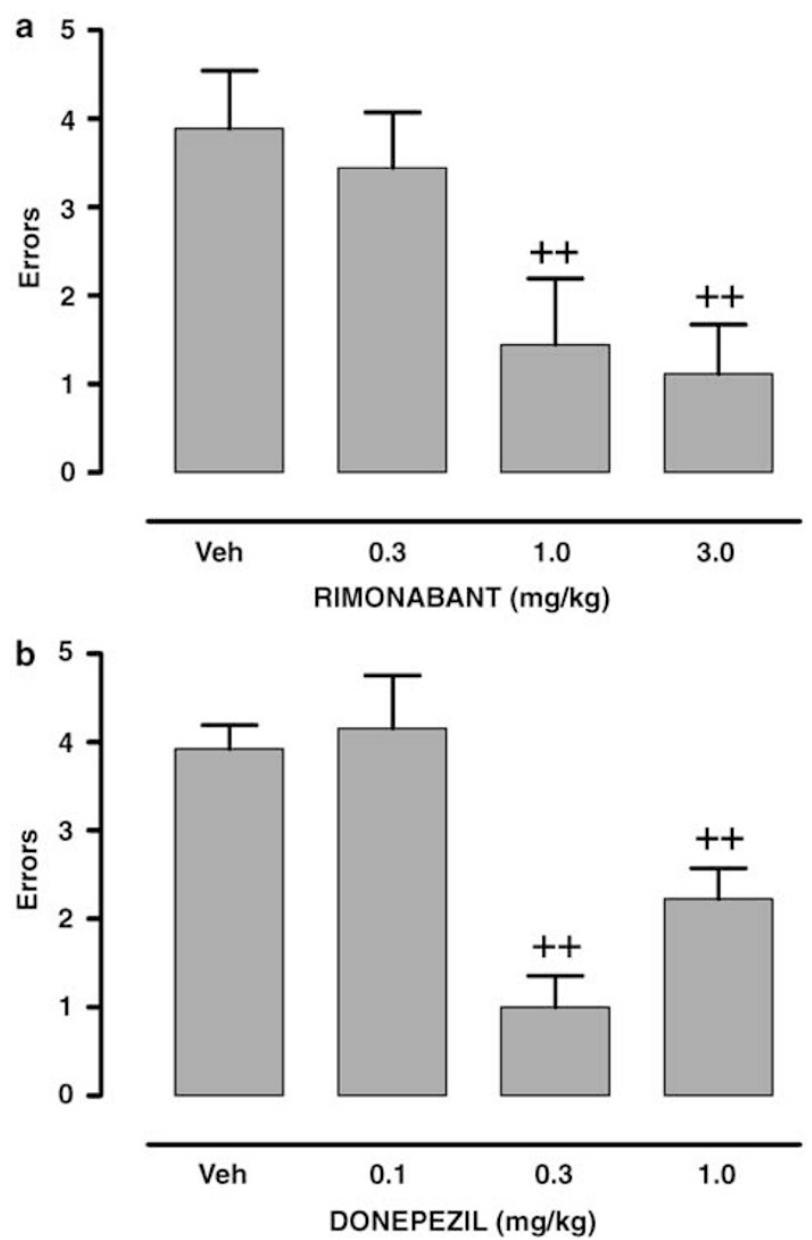

Figure 2 Administered 20 min before the acquisition phase, rimonabant (a) and donepezil (b) decreased the number of errors committed in the test phase. ${ }^{++} p<0.0$ I for each group vs vehicle treatment (Dunnett's post hoc test). Results are shown as mean $\pm \mathrm{SE} ; n=9-14$ rats/group. 

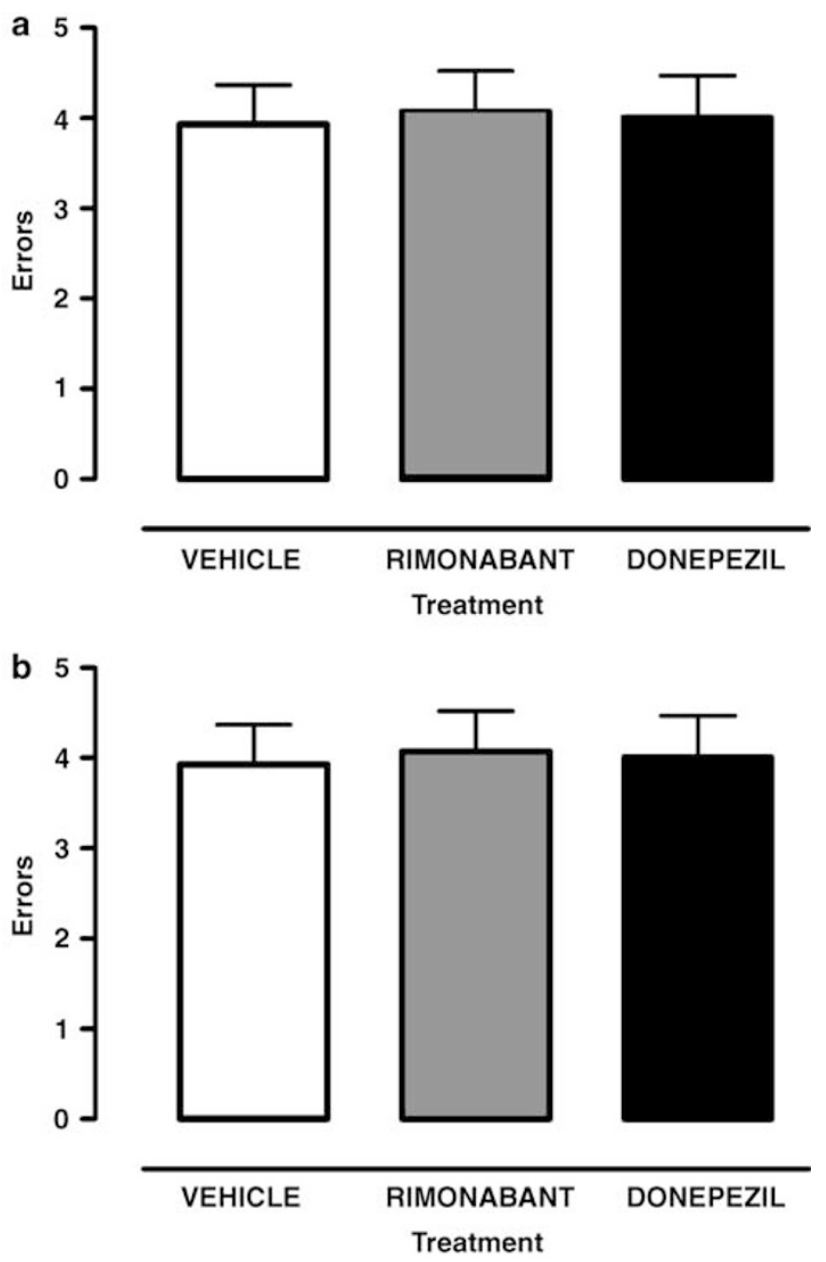

Figure 3 Administered immediately after the acquisition phase (a) or $30 \mathrm{~min}$ before the retrieval test (b), rimonabant $(1.0 \mathrm{mg} / \mathrm{kg}$ ) and donepezil $(0.3 \mathrm{mg} / \mathrm{kg})$ failed to affect the number of errors committed in the test phase. Results are shown as mean $\pm S E ; n=12-14$ rats/group.

In subsequent experiments, we evaluated the impact of injecting effective doses of rimonabant $(1.0 \mathrm{mg} / \mathrm{kg})$ or donepezil $(0.3 \mathrm{mg} / \mathrm{kg})$, immediately following the acquisition phase or $20 \mathrm{~min}$ before the retrieval test phase to determine if these compounds influenced consolidation and memory retrieval process, respectively. As shown in Figure 3, when given either immediately after acquisition or $30 \mathrm{~min}$ before retrieval testing, neither compound enhanced performance during the Phase 2 retrieval test.

\section{Concomitant Administration of Rimonabant and Donepezil Enhances Memory}

Given the observations that rimonabant as well as donepezil administered $20 \mathrm{~min}$ before acquisition significantly improved choice accuracy during the retrieval test $18 \mathrm{~h}$ later, we examined whether combined administration of these drugs would augment each other's memory-enhancing effects. We first re-evaluated single doses of rimonabant $(0,0.3$, and 1.0$)$ and donepezil $(0,0.1$, and $0.3 \mathrm{mg} / \mathrm{kg})$ given alone, as previously shown in Figure 2. Rimonabant reduced the number of errors committed in the retrieval phase, $\mathrm{F}(2,16)=7.9, p<0.01$, with the $1.0 \mathrm{mg} / \mathrm{kg}$ dose $(p<0.01)$, but not the $0.3 \mathrm{mg} / \mathrm{kg}$ dose, eliciting significantly fewer

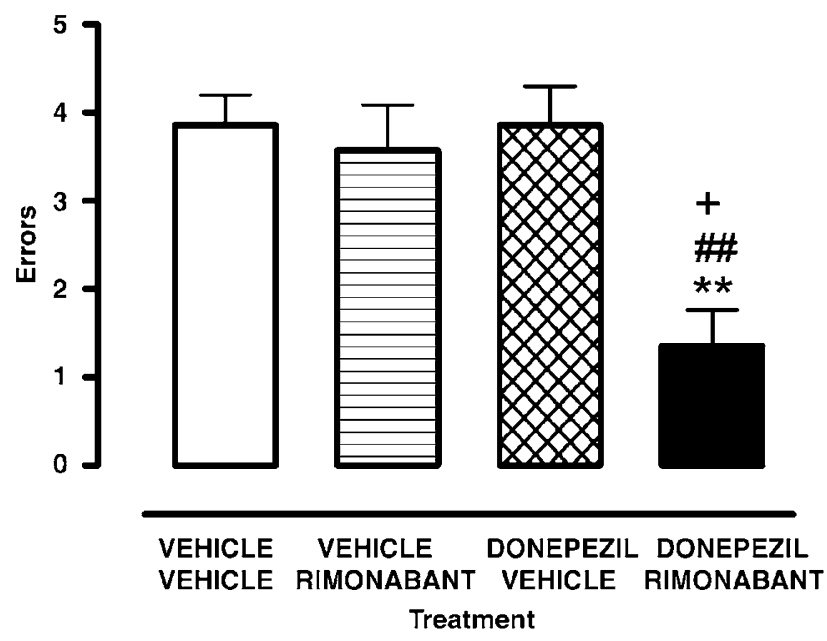

Figure 4 Subthreshold doses of rimonabant $(0.3 \mathrm{mg} / \mathrm{kg})$ and donepezil $(0.1 \mathrm{mg} / \mathrm{kg})$ given in combination decreased the number of errors committed in the test phase. The combination treatment significantly differed from the vehicle condition (** $p<0.01$ ), rimonabant alone condition $\left({ }^{+} p<0.05\right)$, and the donepezil alone condition ( $\left.{ }^{\# \#} p<0.01\right)$. Results are shown as mean \pm SE; $n=14$ rats/group.

errors than that produced by the vehicle treatment (data not shown). Similarly, donepezil reduced the number of errors committed in the retrieval phase, $\mathrm{F}(2,16)=8.5, p<0.01$, with the $0.3 \mathrm{mg} / \mathrm{kg}$ dose $(p<0.01)$, but not the $0.1 \mathrm{mg} / \mathrm{kg}$, dose, improving performance compared to the vehicle treatment (data not shown). Based on these findings and the data depicted in Figure 2, subthreshold doses of rimonabant $(0.3 \mathrm{mg} / \mathrm{kg})$ and donepezil $(0.1 \mathrm{mg} / \mathrm{kg})$ were selected in which subjects received the following four treatments in a randomized order: (1) vehicle-vehicle, (2) donepezilvehicle, (3) rimonabant-vehicle, and (4) donepezil-rimonabant. The subjects were then given acquisition training $20 \mathrm{~min}$ after the injections and were evaluated for choice accuracy in the $18 \mathrm{~h}$ retrieval test. As shown in Figure 4, a significant effect was found, $\mathrm{F}(3,39)=7.0, p<0.01$, with the donepezil-rimonabant treatment resulting in fewer errors than each of the other conditions.

\section{DISCUSSION}

In the present study, we make the novel observation that coadministration of subthreshold doses of the $\mathrm{CB}_{1}$ receptor antagonist rimonabant $(0.3 \mathrm{mg} / \mathrm{kg})$ and the $\mathrm{AChE}$ inhibitor donepezil $(0.1 \mathrm{mg} / \mathrm{kg})$ significantly enhances memory as assessed in a rat delay radial-arm maze task. Importantly, the dose of each drug that enhanced memory when given in combination failed to produce any significant effects in this model when given separately. Higher doses of rimonabant and donepezil given alone improved performance when administered before the acquisition phase. However, these doses of rimonabant and donepezil that enhanced performance when administered before the acquisition phase failed to enhance performance when administered immediately after the acquisition phase or $30 \mathrm{~min}$ before the retrieval test. These results indicate that rimonabant and donepezil improve memory by their actions on acquisition processes rather than on retrieval processes. The observation that inactive doses of rimonabant and donepezil given 
together enhanced memory suggests the possibility that duel $\mathrm{CB}_{1}$ antagonism and $\mathrm{AChE}$ inhibition may effectively enhance memory in patients suffering from dementia or other cognitive disorders. With respect to the memoryenhancing effects of combined administration of donepezil and rimonabant, it will be important to determine the duration of action, the long-term consequences after chronic treatment, and the relevance of these effects to humans.

Inserting an $18 \mathrm{~h}$ delay between the acquisition and retrieval test phases increased task difficulty sufficiently to detect drug-induced enhancement in memory. The possibility that the drug-induced improvements in radial-arm maze performance were due to changes in motivation or locomotor effects, rather than a specific effect on mnemonic processes, is an important consideration. However, the doses of rimonabant and donepezil tested did not affect the rate of entry into the arms and, regardless of drug condition, the subjects always consumed the food pellet. Thus, it is unlikely that the performance-enhancing effects observed here are due to increased salience of the food reward or altered locomotor activity.

The finding that rimonabant enhanced memory when administered before the acquisition phase, but not when administered immediately after the acquisition phase or $20 \mathrm{~min}$ before the test phase is consistent with previous findings from our laboratory (Lichtman, 2000). Using a different version of the radial-arm task in which four arms were blocked, Wolff and Leander (2003) found that $1 \mathrm{mg} / \mathrm{kg}$ rimonabant suspended in a different vehicle (ie $15 \%$ cyclodextrin and tween 80) than used in the present study given immediately after the acquisition phase, but not before the test phase, enhanced performance during the retrieval test. Rimonabant has also been demonstrated to enhance performance in a rodent social recognition memory task, as well as attenuate deficits in aged mice and rats in this same task when administered 5 min after acquisition (Terranova et al, 1996). Similarly, avoidance behavior in an elevated T-maze task in mice was enhanced when rimonabant was administered before or immediately after the acquisition phase, but not before the test phase (Takahashi et al, 2005). Additionally, intrahippocampal administration of rimonabant given before training enhanced memory of food-storing birds for the location of a hidden food reward (Shiflett et al, 2004). In contrast to the present findings and the studies previously discussed (Terranova et al, 1996; Lichtman, 2000; Wolff and Leander, 2003; Shiflett et al, 2004; Takahashi et al, 2005), rimonabant failed to improve memory in a variety of operant tasks (Mansbach et al, 1996; Brodkin and Moerschbaecher, 1997; Mallet and Beninger, 1998; Hampson and Deadwyler, 2000) suggesting that rimonabant may enhance memory that persists for longer periods of time (eg minutes or hours) rather than memory that persists for shorter durations (eg seconds). Clearly, the effectiveness of rimonabant in enhancing performance in memory tests is dependent on a range of factors including specific aspects related to the task and the choice of vehicle. In the present study, rimonabant did not enhance performance when administered immediately after the acquisition phase, suggesting that it does not affect consolidation processes. However, given that the time course of consolidation is unknown, it is possible that the drug administered after training reached the site of action sometime after the consolidation period was complete. Thus, the possibility that this compound affects consolidation cannot be ruled out. Nonetheless, these reports taken together suggest that rimonabant improves memory by enhancing acquisition processes, rather than retrieval processes.

There is a growing body of evidence suggesting that endocannabinoids play a facilitory role in extinction processes. Several studies have demonstrated that disruption of $\mathrm{CB}_{1}$ receptor signaling, through either the administration of receptor antagonists or genetic deletion of this receptor, impairs extinction in conditioned freezing and Morris water maze tasks (Marsicano et al, 2002; Suzuki et al, 2004; Varvel et al, 2005). In these paradigms, the $\mathrm{CB}_{1}$ receptor impaired animals exhibited similar behavior as control animals in acquisition. Curiously, intrahippocampal administration of very low doses of AM251, a structurally similar analog of rimonabant, disrupted passive avoidance learning, but had no effect on a nonaversive open field habituation task (de Oliveira Alvares et al, 2005) when administered immediately after training. Although differences in the paradigms used to assess memory in these studies, such as aversive $v s$ food-motivated tasks, may account for discrepancies in these findings as compared to the present findings, these distinctions indicate the need to elucidate further the role of the endocannabinoid system, as well as $\mathrm{CB}_{1}$ receptor antagonists in different models of memory.

In the present study, donepezil improved memory performance in the radial-arm maze and yielded a similar pattern of results as rimonabant. Both drugs enhanced memory in the radial-arm maze task when given $20 \mathrm{~min}$ before acquisition, but had no effects when administered either immediately after acquisition or $30 \mathrm{~min}$ before the test phase. These findings are similar to a report that donepezil improved memory in a passive avoidance task in young rats when administered before the acquisition phase (Carey et al, 2001). Moreover, these findings are consistent with observations that donepezil improves attention or acquisition processes in patients with Alzheimer's disease (Sahakian and Coull, 1993) and reports that the cholinergic system is involved in attentional processes (Voytko et al, 1994; Muir, 1997; Muir et al, 1999). Several studies have reported that donepezil has no effect or impairs performance in healthy rodents, but that it reverses deficits induced pharmacologically or by brain lesions (Rupniak et al, 1997; Poorheidari et al, 1998; Higgins et al, 2002; Bontempi et al, 2003; Takahashi et al, 2005; Yamada et al, 2005). Donepezil also improves performance of aged rats and mice in the Morris water maze (Hernandez et al, 2006), as well as in spontaneous alternation in the T-maze and in a delayed nonmatch to place task in the radial-arm maze (Bontempi et al, 2003). Additionally, there are reports of donepezil reversing memory deficits induced pharmacologically or by lesions in the radial-arm maze (Braida et al, 1996; Cheng et al, 1996; Cheng and Tang, 1998; Ogura et al, 2000). However, in these studies the effects of donepezil administered alone was not evaluated. Thus, the delay radial-arm procedure used here is unique in that it is the only example of which we are aware that donepezil improves memory in healthy animals. 
Combination drug therapy to improve both cognition and the myriad of symptoms associated with Alzheimer's disease has gained attention in recent years. Beneficial effects have been reported in preclinical models in which donepezil was administered in combination with other putative cognitive enhancers. Concomitant administration of donepezil and selegiline, a monoamine oxidase- $\mathrm{B}$ inhibitor, reversed memory deficits in the Morris water maze induced by the administration of scopolamine or $p$-chlorophenylalanine at doses of these agents not found to reverse memory deficits when given alone (Takahata et al, 2005). Administration of donepezil and FK960, a putative cognitive enhancer of piperazine derivation that is thought to enhance somatostatin release in the hippocampus, at doses found to have no effect when given alone improved learning impairments in a passive avoidance task induced by lesions of the nucleus basalis magnocellularis (Tokita et al, 2002). Additionally, repeated coadministration of donepezil and lercanidipine, an L-type calcium channel blocker, improved memory impairments induced from intracerebroventicular administration of streptozotocin to a greater extent than either drug administered alone in the elevated plus maze and in a passive avoidance task (Sonkusare et al, 2005). The notion that combination therapy may be beneficial in patients with Alzheimer's disease is supported by clinical research. Alzheimer's disease patients treated with memantine and donepezil displayed significantly better outcomes than patients given donepezil alone (Tariot et al, 2004). Additionally, patients treated with memantine and rivastigmine, a dual inhibitor of AChE and BuChE, showed improvements in some cognitive domains compared to when rivastigmine was given alone (Dantoine et al, 2006).

A particular advantage of combination drug therapy is that it offers the prospect of additive or synergistic benefits and the potential to decrease doses of agents that cause unwanted side effects. Alternatively, this pharmacological strategy may be limited because side effects may be more pronounced by combined treatment than by single-drug therapy. Side effects associated with donepezil include nausea, diarrhea, and dizziness (Nordberg and Svensson, 1998; Rogers and Friedhoff, 1998). Likewise, rimonabant has been reported to produce nausea, diarrhea, headache, arthralgia, dizziness, depression, insomnia, and anxiety (Despres et al, 2005; Van Gaal et al, 2005). Although the occurrence of the side effects associated with each of these drugs decreases in frequency at lower doses, the impact of combined drug therapy on these effects is yet to be evaluated. Of consequence, no signs of toxicity or other overt behavioral effects were observed with either drug when administered alone or in combination at subthreshold doses, although it should be noted that the present study was not optimized to assess potential side effects. Nonetheless, it will be important to characterize the side effect profile of combination donepezil and rimonabant therapy, as well as to determine whether any of these potential interactions are relevant to humans.

The mechanism underlying the cognitive-enhancing effects of combined administration of rimonabant and donepezil in the present study is unknown. Because we only examined a single dose of each drug in combination, the nature of the interaction (ie additive or synergistic) is unclear. Certainly, this effect may not be limited to the specific agents tested, as other $\mathrm{AChE}$ inhibitors administered in combination with rimonabant or other $\mathrm{CB}_{1}$ receptor antagonists would also be expected to enhance memory duration. However, one likely possibility for the interaction between these two drugs is through cholinergic systems. Specifically, donepezil's inhibition of cholinesterase leads to increased acetylcholine levels in the synaptic cleft (Giacobini et al, 1996; Kosasa et al, 1999) and rimonabant increases acetylcholine release in the hippocampus (Gifford and Ashby, 1996; Gessa et al, 1997; Gifford et al, 1997a, b, 2000).

Although the combination of subthreshold doses of rimonabant and donepezil may have strengthened memory by enhancing acetylcholine transmission, both drugs also have effects on other neurochemical systems. Specifically, it has been suggested that mechanisms other than enhancement of cholinergic function may be involved in the pharmacology of donepezil efficacy in improving cognition (Narahashi et al, 2004; Moriguchi et al, 2005). Systemic administration of donepezil has been found to increase levels of norepinephrine, dopamine, and serotonin, in addition to its effects on acetylcholine (Cuadra et al, 1994; Giacobini et al, 1996; Shearman et al, 2006). Donepezil also has been shown to potentiate NMDAinduced currents in multipolar and bipolar neurons (Moriguchi et al, 2005), as well as to produce NMDA receptor blockade and have agonist-like activity at sigma receptors (Maurice et al, 2006). Rimonabant is thought to produce its effects by either antagonizing a tonically active endogenous cannabinoid system or through its actions as an inverse agonist (Landsman et al, 1997). One of the primary effects of cannabinoid agonists in the hippocampus, as well as other brain regions, is to inhibit neurotransmitter release; thus, it is not surprising that rimonabant increases not only acetylcholine release (Gifford and Ashby, 1996; Gessa et al, 1997; Gifford et al, 1997b, 2000), but also increases glutamatergic transmission (Auclair et al, 2000; Melis et al, 2004). There is a need to elucidate the specific mechanisms underlying the interaction between donepezil and rimonabant in future studies.

In conclusion, the present study demonstrates that the specific antagonist of the $\mathrm{CB}_{1}$ receptor, rimonabant, and the selective noncompetitive inhibitor of $\mathrm{AChE}$, donepezil, have memory enhancing effects in a delay task in the radial-arm maze. Each of these drugs improves memory by acting on acquisition processes, rather than retrieval processes. A key finding was that subthreshold doses of a combination of rimonabant and donepezil enhanced performance in this task. Taken together, these findings suggest that low doses of $\mathrm{CB}_{1}$ receptor antagonists and $\mathrm{AChE}$ inhibitors given in combination may optimize the beneficial therapeutic actions in patients with dementia or other cognitive disorders.

\section{ACKNOWLEDGEMENTS}

This research was supported by the National Institute on Drug Abuse (DA015683 and T23DA07027) and Pfizer Inc. 


\section{REFERENCES}

Auclair N, Otani S, Soubrie P, Crepel F (2000). Cannabinoids modulate synaptic strength and plasticity at glutamatergic synapses of rat prefrontal cortex pyramidal neurons. J Neurophysiol 83: 3287-3293.

Bontempi B, Whelan KT, Risbrough VB, Lloyd GK, Menzaghi F (2003). Cognitive enhancing properties and tolerability of cholinergic agents in mice: a comparative study of nicotine, donepezil, and SIB-1553A, a subtype-selective ligand for nicotinic acetylcholine receptors. Neuropsychopharmacology 28: 1235-1246.

Braida D, Paladini E, Griffini P, Lamperti M, Maggi A, Sala M (1996). An inverted U-shaped curve for heptylphysostigmine on radial maze performance in rats: comparison with other cholinesterase inhibitors. Eur J Pharmacol 302: 13-20.

Brodkin J, Moerschbaecher JM (1997). SR141716A antagonizes the disruptive effects of cannabinoid ligands on learning in rats. J Pharmacol Exp Ther 282: 1526-1532.

Carey GJ, Billard W, Binch III H, Cohen-Williams M, Crosby G, Grzelak M et al (2001). SCH 57790, a selective muscarinic M(2) receptor antagonist, releases acetylcholine and produces cognitive enhancement in laboratory animals. Eur J Pharmacol 431: 189-200.

Cheng DH, Ren H, Tang XC (1996). Huperzine A, a novel promising acetylcholinesterase inhibitor. Neuroreport 8: 97-101.

Cheng DH, Tang XC (1998). Comparative studies of huperzine A, E2020, and tacrine on behavior and cholinesterase activities. Pharmacol Biochem Behav 60: 377-386.

Cuadra G, Summers K, Giacobini E (1994). Cholinesterase inhibitor effects on neurotransmitters in rat cortex in vivo. J Pharmacol Exp Ther 270: 277-284.

Dantoine T, Auriacombe S, Sarazin M, Becker H, Pere JJ, Bourdeix I (2006). Rivastigmine monotherapy and combination therapy with memantine in patients with moderately severe Alzheimer's disease who failed to benefit from previous cholinesterase inhibitor treatment. Int J Clin Pract 60: $110-118$.

Davies P, Maloney AJ (1976). Selective loss of central cholinergic neurons in Alzheimer's disease. Lancet 2: 1403.

de Oliveira Alvares L, de Oliveira LF, Camboim C, Diehl F, Genro BP, Lanziotti VB et al (2005). Amnestic effect of intrahippocampal AM251, a CB1-selective blocker, in the inhibitory avoidance, but not in the open field habituation task, in rats. Neurobiol Learn Mem 83: 119-124.

de Oliveira Alvares L, Pasqualini Genro B, Vaz Breda R, Pedroso MF, Costa Da Costa J, Quillfeldt JA (2006). AM251, a selective antagonist of the CB1 receptor, inhibits the induction of longterm potentiation and induces retrograde amnesia in rats. Brain Res 1075: 60-67.

Despres JP, Golay A, Sjostrom L (2005). Effects of rimonabant on metabolic risk factors in overweight patients with dyslipidemia. $N$ Engl J Med 353: 2121-2134.

Devane WA, Hanus L, Breuer A, Pertwee RG, Stevenson LA, Griffin $\mathrm{G}$ et al (1992). Isolation and structure of a brain constituent that binds to the cannabinoid receptor. Science 258: 1946-1949.

Di Marzo V, Breivogel CS, Tao Q, Bridgen DT, Razdan RK, Zimmer $\mathrm{AM}$ et al (2000). Levels, metabolism, and pharmacological activity of anandamide in $\mathrm{CB}(1)$ cannabinoid receptor knockout mice: evidence for non- $\mathrm{CB}(1)$, non- $\mathrm{CB}(2)$ receptor-mediated actions of anandamide in mouse brain. J Neurochem 75: 2434-2444.

Doody RS (1999). Clinical profile of donepezil in the treatment of Alzheimer's disease. Gerontology 45(Suppl 1): 23-32.

Felder CC, Nielsen A, Briley EM, Palkovits M, Priller J, Axelrod J et al (1996). Isolation and measurement of the endogenous cannabinoid receptor agonist, anandamide, in brain and peripheral tissues of human and rat. FEBS Lett 393: 231-235.

Gessa GL, Mascia MS, Casu MA, Carta G (1997). Inhibition of hippocampal acetylcholine release by cannabinoids: reversal by SR 141716A. Eur J Pharmacol 327: R1-R2.

Giacobini E, Zhu XD, Williams E, Sherman KA (1996). The effect of the selective reversible acetylcholinesterase inhibitor E2020 on extracellular acetylcholine and biogenic amine levels in rat cortex. Neuropharmacology 35: 205-211.

Gifford AN, Ashby Jr CR (1996). Electrically evoked acetylcholine release from hippocampal slices is inhibited by the cannabinoid receptor agonist, WIN 55212-2, and is potentiated by the cannabinoid antagonist, SR 141716A. J Pharmacol Exp Ther 277: 1431-1436.

Gifford AN, Bruneus M, Gatley SJ, Volkow ND (2000). Cannabinoid receptor-mediated inhibition of acetylcholine release from hippocampal and cortical synaptosomes. Br J Pharmacol 131: 645-650.

Gifford AN, Samiian L, Gatley SJ, Ashby Jr CR (1997a). Examination of the effect of the cannabinoid receptor agonist, CP 55,940, on electrically evoked transmitter release from rat brain slices. Eur J Pharmacol 324: 187-192.

Gifford AN, Tang Y, Gatley SJ, Volkow ND, Lan R, Makriyannis A (1997b). Effect of the cannabinoid receptor SPECT agent, AM 281, on hippocampal acetylcholine release from rat brain slices. Neurosci Lett 238: 84-86.

Grutzendler J, Morris JC (2001). Cholinesterase inhibitors for Alzheimer's disease. Drugs 61: 41-52.

Hampson RE, Deadwyler SA (2000). Cannabinoids reveal the necessity of hippocampal neural encoding for short-term memory in rats. J Neurosci 20: 8932-8942.

Herkenham M, Lynn AB, Johnson MR, Melvin LS, de Costa BR, Rice KC (1991). Characterization and localization of cannabinoid receptors in rat brain: a quantitative in vitro autoradiographic study. J Neurosci 11: 563-583.

Hernandez CM, Gearhart DA, Parikh V, Hohnadel EJ, Davis LW, Middlemore ML et al (2006). Comparison of galantamine and donepezil for effects on nerve growth factor, cholinergic markers, and memory performance in aged rats. J Pharmacol Exp Ther 316: 679-694.

Higgins GA, Enderlin M, Fimbel R, Haman M, Grottick AJ, Soriano $M$ et al (2002). Donepezil reverses a mnemonic deficit produced by scopolamine but not by perforant path lesion or transient cerebral ischaemia. Eur J Neurosci 15: 1827-1840.

Kosasa T, Kuriya Y, Matsui K, Yamanishi Y (1999). Inhibitory effects of donepezil hydrochloride (E2020) on cholinesterase activity in brain and peripheral tissues of young and aged rats. Eur J Pharmacol 386: 7-13.

Landsman RS, Burkey TH, Consroe P, Roeske WR, Yamamura HI (1997). SR141716A is an inverse agonist at the human cannabinoid CB1 receptor. Eur J Pharmacol 334: R1-R2.

Lichtman AH (2000). SR 141716A enhances spatial memory as assessed in a radial-arm maze task in rats. Eur J Pharmacol 404: $175-179$.

Lichtman AH, Martin BR (1996). Delta 9-tetrahydrocannabinol impairs spatial memory through a cannabinoid receptor mechanism. Psychopharmacology (Berlin) 126: 125-131.

Mallet PE, Beninger RJ (1998). The cannabinoid CB1 receptor antagonist SR141716A attenuates the memory impairment produced by delta9-tetrahydrocannabinol or anandamide. Psychopharmacology (Berlin) 140: 11-19.

Mansbach RS, Rovetti CC, Winston EN, Lowe III JA (1996). Effects of the cannabinoid CB1 receptor antagonist SR141716A on the behavior of pigeons and rats. Psychopharmacology (Berlin) 124: 315-322.

Marsicano G, Wotjak CT, Azad SC, Bisogno T, Rammes G, Cascio MG et al (2002). The endogenous cannabinoid system controls extinction of aversive memories. Nature 418: 530-534. 
Matsuda LA, Lolait SJ, Brownstein MJ, Young AC, Bonner TI (1990). Structure of a cannabinoid receptor and functional expression of the cloned cDNA. Nature 346: 561-564.

Maurice T, Meunier J, Feng B, Ieni J, Monaghan DT (2006). Interaction with \{sigma\} 1 protein, but not NMDA receptor, is involved in the pharmacological activity of donepezil. $J$ Pharmacol Exp Ther 317: 606-614.

Mechoulam R, Ben-Shabat S, Hanus L, Ligumsky M, Kaminski NE, Schatz AR et al (1995). Identification of an endogenous 2monoglyceride, present in canine gut, that binds to cannabinoid receptors. Biochem Pharmacol 50: 83-90.

Melis M, Pistis M, Perra S, Muntoni AL, Pillolla G, Gessa GL (2004). Endocannabinoids mediate presynaptic inhibition of glutamatergic transmission in rat ventral tegmental area dopamine neurons through activation of $\mathrm{CB} 1$ receptors. $J$ Neurosci 24: 53-62.

Mintzer JE, Kershaw P (2003). The efficacy of galantamine in the treatment of Alzheimer's disease: comparison of patients previously treated with acetylcholinesterase inhibitors to patients with no prior exposure. Int J Geriatr Psychiatry 18: 292-297.

Moriguchi S, Zhao X, Marszalec W, Yeh JZ, Narahashi T (2005). Modulation of $\mathrm{N}$-methyl-D-aspartate receptors by donepezil in rat cortical neurons. J Pharmacol Exp Ther 315: 125-135.

Muir JL (1997). Acetylcholine, aging, and Alzheimer's disease. Pharmacol Biochem Behav 56: 687-696.

Muir JL, Fischer W, Bjorklund A (1999). Decline in visual attention and spatial memory in aged rats. Neurobiol Aging 20: 605-615.

Narahashi T, Moriguchi S, Zhao X, Marszalec W, Yeh JZ (2004). Mechanisms of action of cognitive enhancers on neuroreceptors. Biol Pharm Bull 27: 1701-1706.

Nordberg A, Svensson AL (1998). Cholinesterase inhibitors in the treatment of Alzheimer's disease: a comparison of tolerability and pharmacology. Drug Saf 19: 465-480.

Ogura H, Kosasa T, Kuriya Y, Yamanishi Y (2000). Donepezil, a centrally acting acetylcholinesterase inhibitor, alleviates learning deficits in hypocholinergic models in rats. Methods Find Exp Clin Pharmacol 22: 89-95.

Perry EK, Perry RH, Blessed G, Tomlinson BE (1978a). Changes in brain cholinesterases in senile dementia of Alzheimer type. Neuropathol Appl Neurobiol 4: 273-277.

Perry EK, Tomlinson BE, Blessed G, Bergmann K, Gibson PH, Perry RH (1978b). Correlation of cholinergic abnormalities with senile plaques and mental test scores in senile dementia. BMJ 2: 1457-1459.

Poorheidari G, Stanhope KJ, Pratt JA (1998). Effects of the potassium channel blockers, apamin and 4-aminopyridine, on scopolamine-induced deficits in the delayed matching to position task in rats: a comparison with the cholinesterase inhibitor E2020. Psychopharmacology (Berlin) 135: 242-255.

Reibaud M, Obinu MC, Ledent C, Parmentier M, Bohme GA, Imperato A (1999). Enhancement of memory in cannabinoid CB1 receptor knock-out mice. Eur J Pharmacol 379: R1-R2.

Rinaldi-Carmona M, Barth F, Heaulme M, Alonso R, Shire D, Congy C et al (1995). Biochemical and pharmacological characterisation of SR141716A, the first potent and selective brain cannabinoid receptor antagonist. Life Sci 56: 1941-1947.

Rogers SL, Friedhoff LT (1998). Long-term efficacy and safety of donepezil in the treatment of Alzheimer's disease: an interim analysis of the results of a US multicentre open label extension study. Eur Neuropsychopharmacol 8: 67-75.

Rupniak NM, Tye SJ, Field MJ (1997). Enhanced performance of spatial and visual recognition memory tasks by the selective acetylcholinesterase inhibitor E2020 in rhesus monkeys. Psychopharmacology (Berlin) 131: 406-410.

Sahakian BJ, Coull JT (1993). Tetrahydroaminoacridine (THA) in Alzheimer's disease: an assessment of attentional and mnemonic function using CANTAB. Acta Neurol Scand Suppl 149: 29-35.

Shearman E, Rossi S, Szasz B, Juranyi Z, Fallon S, Pomara N et al (2006). Changes in cerebral neurotransmitters and metabolites induced by acute donepezil and memantine administrations: a microdialysis study. Brain Res Bull 69: 204-213.

Shiflett MW, Rankin AZ, Tomaszycki ML, DeVoogd TJ (2004). Cannabinoid inhibition improves memory in food-storing birds, but with a cost. Proc Biol Sci 271: 2043-2048.

Sonkusare S, Srinivasan K, Kaul C, Ramarao P (2005). Effect of donepezil and lercanidipine on memory impairment induced by intracerebroventricular streptozotocin in rats. Life Sci 77: 1-14.

Sugimoto H, Ogura H, Arai Y, Limura Y, Yamanishi Y (2002). Research and development of donepezil hydrochloride, a new type of acetylcholinesterase inhibitor. Jpn J Pharmacol 89: 7-20.

Sugiura T, Kondo S, Sukagawa A, Nakane S, Shinoda A, Itoh K et al (1995). 2-Arachidonoylglycerol: a possible endogenous cannabinoid receptor ligand in brain. Biochem Biophys Res Commun 215: 89-97.

Suzuki A, Josselyn SA, Frankland PW, Masushige S, Silva AJ, Kida $S$ (2004). Memory reconsolidation and extinction have distinct temporal and biochemical signatures. J Neurosci 24: 4787-4795.

Takahashi RN, Pamplona FA, Fernandes MS (2005). The cannabinoid antagonist SR141716A facilitates memory acquisition and consolidation in the mouse elevated T-maze. Neurosci Lett 380: 270-275.

Takahata K, Minami A, Kusumoto H, Shimazu S, Yoneda F (2005). Effects of selegiline alone or with donepezil on memory impairment in rats. Eur J Pharmacol 518: 140-144.

Tariot PN, Farlow MR, Grossberg GT, Graham SM, McDonald S, Gergel I (2004). Memantine treatment in patients with moderate to severe Alzheimer disease already receiving donepezil: a randomized controlled trial. JAMA 291: 317-324.

Terranova JP, Storme JJ, Lafon N, Perio A, Rinaldi-Carmona M, Le Fur $\mathrm{G}$ et al (1996). Improvement of memory in rodents by the selective CB1 cannabinoid receptor antagonist, SR 141716. Psychopharmacology (Berlin) 126: 165-172.

Tokita K, Yamazaki S, Yamazaki M, Matsuoka N, Mutoh S (2002). Combination of a novel antidementia drug FK960 with donepezil synergistically improves memory deficits in rats. Pharmacol Biochem Behav 73: 511-519.

Van Gaal LF, Rissanen AM, Scheen AJ, Ziegler O, Rossner S (2005). Effects of the cannabinoid-1 receptor blocker rimonabant on weight reduction and cardiovascular risk factors in overweight patients: 1-year experience from the RIO-Europe study. Lancet 365: 1389-1397.

Varvel SA, Anum EA, Lichtman AH (2005). Disruption of CB(1) receptor signaling impairs extinction of spatial memory in mice. Psychopharmacology (Berlin) 179: 863-872.

Voytko ML, Olton DS, Richardson RT, Gorman LK, Tobin JR, Price DL (1994). Basal forebrain lesions in monkeys disrupt attention but not learning and memory. J Neurosci 14: 167-186.

Wolff MC, Leander JD (2003). SR141716A, a cannabinoid CB1 receptor antagonist, improves memory in a delayed radial maze task. Eur J Pharmacol 477: 213-217.

Yamada K, Takayanagi M, Kamei H, Nagai T, Dohniwa M, Kobayashi $\mathrm{K}$ et al (2005). Effects of memantine and donepezil on amyloid beta-induced memory impairment in a delayed-matching to position task in rats. Behav Brain Res 162: 191-199. 